\title{
NPA IN THE DOCK Thumbs up for the prosecution service
}

Martin Schönteich, Institute for Security Studies

martin.s@iss.co.za

G eneral public confidence in the criminal justice system and the government's handling of crime is low, according to an Institute for Security Studies survey. Yet, most people trust the police and would willingly give evidence in court. People who have been to court as state witnesses are more positive about the work of the prosecution service compared to those who have not. Indeed, most court users have a positive opinion of prosecutors and the work they do. D issatisfaction is primarily a result of lengthy delays in trials, and unhelpful and unprofessional prosecutors.

$\mathrm{I}$ n late 2001, the Institute for Security Studies (ISS) conducted an opinion survey to evaluate the services provided by the National Prosecuting Authority (NPA). The survey covered the general public, as well as crime victims and state witnesses who interacted with prosecutors in 18 magistrates' courts throughout the country.

The N PA commissioned the ISS to conduct the survey, and intends using the survey results to develop performance indicators and to improve its service to the public and court users.

\section{General public perceptions}

The largest part of the survey sought to measure perceptions the general public has of, among other things, the performance of the criminal justice system and the role of the prosecution service. Some 210 randomly selected people, who lived within a few kilometres of the selected court sites, were interviewed per site. In total 18 courts were selected (two per province), and 3,830 people were interviewed.

O verall, the respondents were fairly representative of the general South African population, with coloured, white, and female respondents slightly overrepresented. The majority of respondents lived in an urban area, were young to middle-aged (21 to 40 years) and had a relatively high level of education
(57\% had completed matric). Almost half $(47 \%)$ were employed in either the formal or informal sector.

Close to a third $(29 \%)$ of the respondents stated that they had been a victim of a crime in the two years prior to the survey. Of these respondents, 79\% reported the matter to the police. However, only four out of ten $(39 \%)$ respondents who reported the crime were satisfied with the police's response. This could be because over three-quarters (76\%) of the reported cases did not end up in court.

O verall, respondents were negative about the general functioning of the criminal justice system since 1994, and the government's role in fighting crime. Nevertheless, the majority of respondents indicated a willingness to report crime to the police and give evidence in court (Figure 1).

W hile almost half (49\%) of the respondents had been inside a criminal court in the ten years prior to the survey, only $54 \%$ knew what the function of the prosecution service is. This may be because many of the respondents who had attended court did so simply to watch or to provide support to a relative or friend. Just over a quarter $(28 \%)$ of respondents said they had ever met a prosecutor.

When asked how good a job the prosecution service generally is doing, three-quarters of the respondents 
stated either "okay" or "good" (51\% and $24 \%$, respectively). O nly 15\% thought the prosecution service was generally doing a "bad" job.

To gauge what the general public thinks of the different professions in the criminal justice field, respondents were asked what profession they would choose for their children given the following choices: police officer, detective, magistrate, prosecutor, lawyer in private practice, or none of these.

The most common response, given by $40 \%$ of the respondents, was "none of these", i.e. none of the given career choices in the criminal justice field. This answer was followed by "lawyer in private practice" (35\%), magistrate $(11 \%)$, prosecutor $(5 \%)$, and police officer and detective (both $4 \%$ ).

When asked to rank the different components of the NPA in terms of perceived effectiveness, respondents ranked the Scorpions as the most effective NPA component (with $84 \%$ of respondents stating that the Scorpions were effective). This was followed by the Asset Forfeiture U nit (64\%). Interestingly, only 58\% of the respondents thought that the Directorate of Special O perations (DSO) was effective. The DSO is the official name of the Scorpions, and the response indicates that many people do not know that the DSO and the Scorpions are the same organisation (Figure 2).

\section{Court users' perceptions}

A second aspect of the survey gauged the opinions of court users: people who interacted with the prosecution service as state witnesses or crime victims. O ne hundred interviews were conducted per
Figure 1: Proportion of respondents who said ...

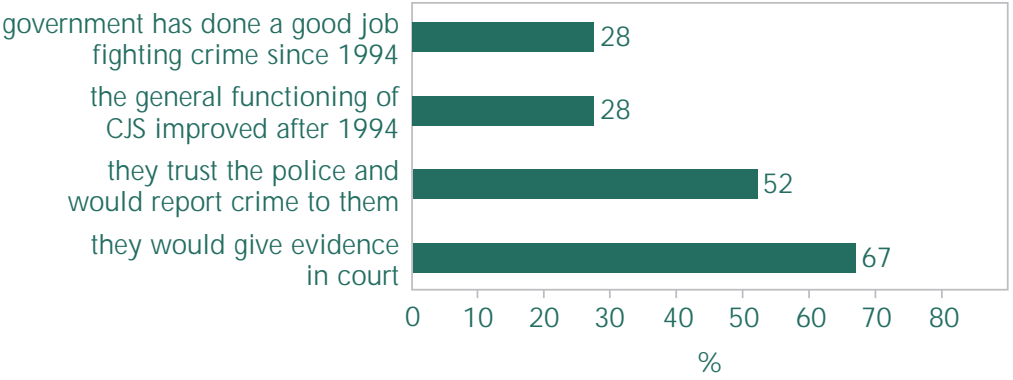

Source: ISS perception survey of public and court users, 2001

Figure 2: Effectiveness ratings of NPA components

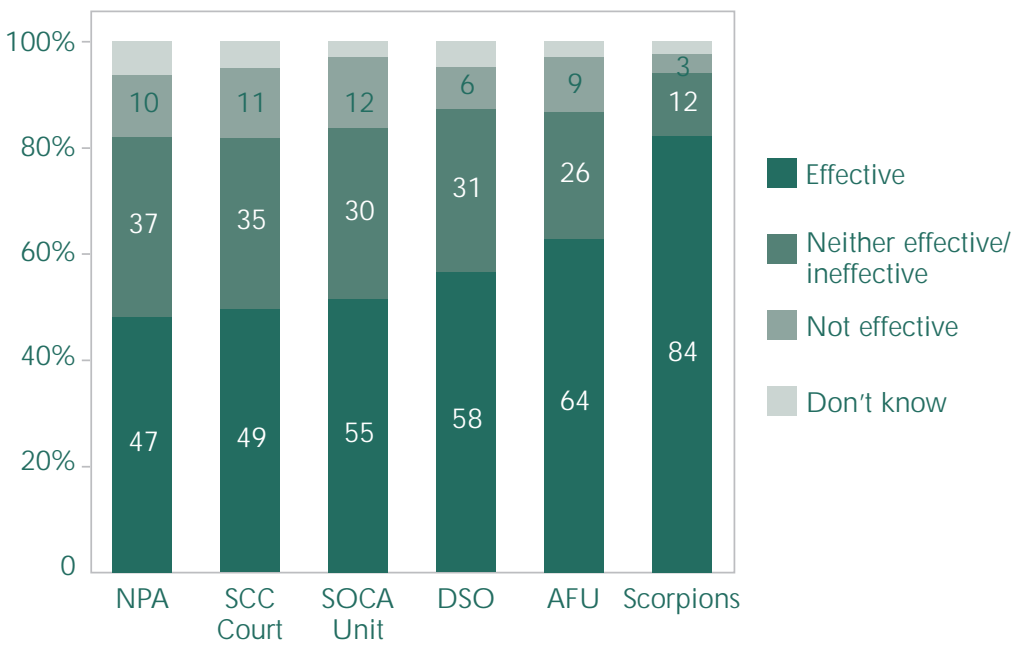

SCC = Specialised Commercial Crimes; SO CA = Sexual O ffences and Community Affairs Source: ISS perception survey of public and court users, 2001

court site, covering 50 state witnesses and 50 witnesses who were victims of crime in the cases before court. People were interviewed as they were leaving the court building.

Interestingly, the opinions of court users were more positive about the work of the NPA compared to people who had not used the courts. Of the 1,800 state witnesses and crime victims surveyed countrywide, the vast majority said that the prosecutor they had dealt with was willing to help them, and that the prosecutor understood their concerns (Figure 3).

Court users gave two main reasons why they were satisfied with a prosecutor's service. Firstly, because the prosecutor was helpful, competent and treated 
them with respect and professionalism. Secondly, because the prosecutor informed them about the justice process and what to expect in court.

According to the survey, court users were most likely to be dissatisfied with the service provided by prosecutors because of frequent postponements, numerous delays in the court process, and a lack of information provided by prosecutors. For example, about half $(53 \%)$ of court users said that the prosecutor handling their case had not identified him/herself to them. This comment was highest among black respondents, with $59 \%$ stating that the prosecutor did not identify him/herself, followed by coloured $(42 \%)$, white $(37 \%)$ and Indian $(26 \%)$ respondents.

The success of a prosecution usually depends on the credibility and cogency of the testimony given by the state's witnesses. Given this it is disappointing that $43 \%$ of respondents felt that the prosecutor had not explained what was expected of them in court. Moreover, only $64 \%$ of the respondents stated that they had received assistance from the prosecutor in going through their written statement. Coloured and white respondents were significantly more likely than black and Indian respondents to state that the prosecutor had assisted them in going through their written statement (Figure 4).

On the whole, just under a fifth $(18 \%)$ of the respondents felt the prosecutor would have treated them in a better way if they had been of a different race. Among black and Indian respondents $22 \%$ thought so, while only $10 \%$ of coloured and $6 \%$ of white respondents had this perception.

The survey revealed that state witnesses experience numerous delays before testifying. Some two-thirds $(67 \%)$ of the respondents said they were not informed by the prosecutor as to how long they would have to wait before their case was heard. Almost a third (32\%) of respondents had their case postponed on the day of the interview. Of the
Figure 3: Proportion of respondents who said ...

ir human rights were

respected and protected 88

during court appearances

the prosecutor was willing

to help
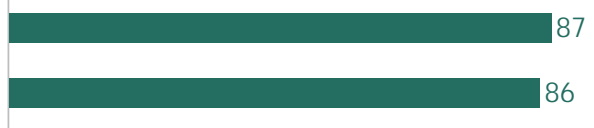
their concerns

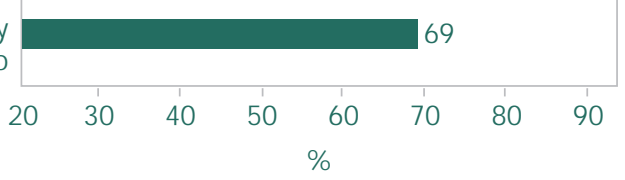

$\%$

y of public and court users, 2001

Figure 4: Those who said the prosecutor assisted them by going through their written statement

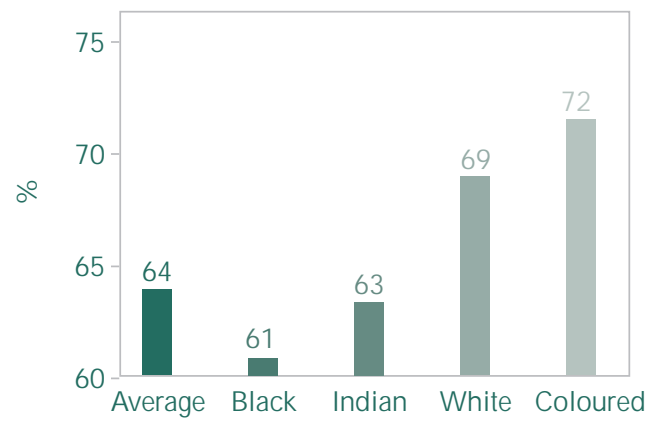

Source: ISS perception survey of public and court users, 2001

respondents whose cases were postponed, only a third $(33 \%)$ were consulted about a new trial date that would be suitable to them.

Most of the respondents said the case in which they had to testify was postponed between one and five times without ever giving evidence in court. O nly one respondent in four managed to testify on the day they appeared in court for the first time to give evidence (Figure 5).

While court users were dissatisfied with some service standards, they expressed a high opinion of the professional competence of prosecutors. O ver four-fifths $(82 \%)$ of court users said that prosecutors know "more" or "the same" as defence attorneys. Moreover, $89 \%$ of respondents thought that the prosecutor who was dealing with them knew what to do with their case. 
Figure 5: Proportion of respondents whose cases were postponed without them testifying

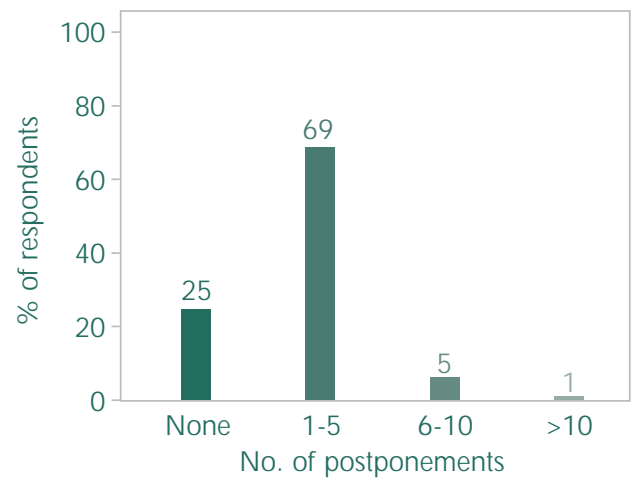

Source: ISS perception survey of public and court users, 2001

O verall, $12 \%$ of respondents felt that, having attended court, their perceptions of the effectiveness of the criminal justice system worsened because of their experiences at court. W hite respondents were most likely to say this (26\%) (Figure 6).

Significantly, of the respondents who felt that their perceptions of the criminal justice system had worsened, only $47 \%$ would in future report a crime to the police if they became a victim of crime, knowing that they might have to go through a similar process and give evidence in court. Among black respondents whose perceptions of the criminal justice system had worsened, only 35\% stated that they would in future again report a crime to the police.

W hen asked why their perceptions of the criminal justice system had worsened, most respondents said it was because "criminals walk free" $(27 \%)$, followed by "unhelpful/disrespectful court personnel" (15\%), "court process too slow" (15\%), and "sentences too lenient" ( $12 \%)$. O nly $5 \%$ gave as the reason for their dissatisfaction "bias or racism", with $4 \%$ stating "corruption".

\section{Conclusion}

Encouragingly, the perceptions of the courts and the prosecution service are more positive among those respondents who have actually experienced the service offered by prosecutors, compared to the general public.
Figure 6: Respondents whose perceptions of CJS worsened having attended court, but who would still report crime in the future

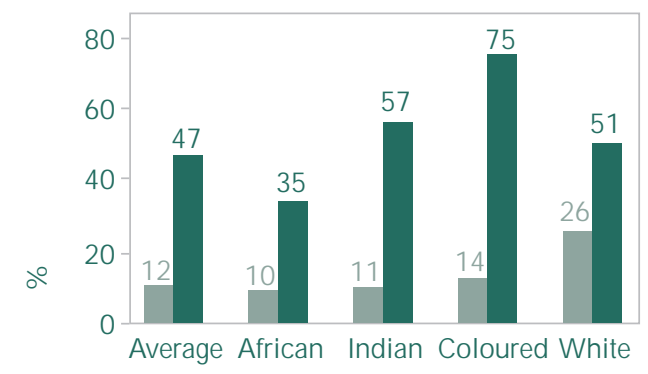

Perceptions of CIS worsened

Source: ISS perception survey of public and court users, 2001

The main expectations state witnesses and crime victims have when they go to court are of receiving a professional and competent service, being informed about the court procedure and their role within that process, and to not be unreasonably delayed. Most of these expectations are reasonable and can be met in an inexpensive manner. They primarily require a change in prosecutors' attitudes to service delivery, and professional and friendly conduct.

O verall, given the delays state witnesses face, they are surprisingly positive about the services provided by prosecutors. O $\mathrm{n}$ most performance indicators prosecutors have fared very well. This should not be a reason for complacency, however. There are a number of individual courts covered in the survey where respondents' perceptions of the services provided by prosecutors were consistently below the national average.

Moreover, while only one out of eight respondents who attended court felt that their perceptions of the effectiveness of the criminal justice system worsened because of their experiences at court, almost half of them would in future not report a crime to the police. In order to function, the criminal justice system relies on the co-operation of the public. Without public support the relevance of the system diminishes, resulting in a loss of public trust in the state's ability to protect them from crime. This, in turn, may encourage vigilantism and mob justice. 